\title{
Constructivismo y Teoría de la Historia
}

\section{Constructivism and the History's Theory}

\author{
Carlos Arturo Londoño Ramos \\ Universidad Pedagógica y Tecnológica de Colombia \\ londonocarlosarturo@hotmail.com
}

Fecha de recepción: 24 de abril de 2014

Fecha de aceptación: 23 de julio de 2014

\section{Resumen}

En su filosofía, Hegel considera que la finalidad de la historia es la conquista de la libertad, en consonancia con el derecho racional universal y el desarrollo de la cultura intelectual (el espíritu). El progreso en el espíritu es generado por la toma de conciencia de sí y por los principios éticos, que se universalizan, así como también se realiza (se extraña) objetivamente como institución jurídica y a través de la nación. A diferencia de este idealismo histórico hegeliano, Marx sustenta el materialismo histórico, para el cual las estructuras político-jurídicas y de la conciencia social están condicionadas "en última instancia" por la estructura socioeconómica. Habermas, finalmente, intenta reconstruir el materialismo histórico apoyándose en el aprendizaje intelectivo y construido del conocimiento, la moral y la comunicación, a partir especialmente de Piaget y Kohlberg. Esta reconstrucción de la teoría de la historia significa un "retorno" a la filosofía hegeliana, pero en un nuevo nivel, pues se apoya en las ciencias reconstructivas del aprendizaje inteligente.

Palabras clave: Constructivismo, Materialismo histórico, Teoría de la historia.

\section{Abstract}

Hegel in his philosophy, considers that the History's aim is to conquer liberty, according with the universal rational right and the intellectual cultural development 
(the spirit).The spiritual progress is generated by becoming conscious oneself, and by the universalized ethical principles, and also it is to be objectively realized (externalized) as a judicial institution through the Nation. Different from this Hegelian historical idealism, Marx sustains the historical materialism, for which the political-judicial structures, and the social consciousness are conditioned "at last instance" by the social economic structure. Habermas, finally tries to rebuild the Historical Materialism, supporting himself on the intellectual learning built from knowledge, morality and communication, taken form Peaget and Kohlberg. That History Theory's reconstruction means a "return" to the Hegelian philosophy, but in a new level.

Keywords: Constructivism, Historical Materialism, History's Theory

\section{Introducción}

En la época actual ha crecido el escepticismo acerca de las posibilidades de una teoría y una filosofía de la historia universal, tal como de diversas maneras lo propusieron Kant, Hegel y Marx; estas dudas surgen por una mayor conciencia de la diversidad cultural, que hace muy difícil hacer propuestas "unificadas" sobre el pasado, así como también se tornan cuestionables los ideales del porvenir. No obstante, de forma simultánea, con una mayor preocupación por la identidad de los pueblos que ha llevado al resurgimiento de ciertos nacionalismos y culturas, en especial las religiosas, los organismos internacionales y el sentir de la comunidad académica mundial siguen abogando por los derechos humanos, por la defensa de las libertades fundamentales y por el respeto a las diferencias de las formas de vida.

¿Cómo se puede defender un pluralismo razonable, tanto de las formas de vida de los individuos como de los pueblos, y simultáneamente defender unos principios que desde la modernidad se consideran universales? ¿Cómo sustentar la universalidad al mismo tiempo que se lucha por las posibilidades de la heterogeneidad? En la actualidad, las ciencias, las disciplinas del saber y sus aplicaciones (tomadas en sentido amplio), el derecho, la participación democrática, las artes y la educación escolar se han tornado planetarias; esta nueva condición obedece a que, según la filosofía moderna, en especial la de Kant y Hegel, estos desarrollos constituyen la expresión de la mayoría de edad intelectual. Para Kant, la modernidad está dada por la libertad de pensamiento y las constituciones republicanas, y, para Hegel, se manifiesta en el desarrollo del espíritu, entendiendo por tal los desenvolvimientos de las ciencias, los deberes y derechos jurídicos institucionalizados y la reapropiación de la cultura espiritual (el arte, la religión como metáfora y la fillosofía). No obstante, este desenvolvimiento del espíritu requiere de la educación y, a su vez, la educación compendia el desarrollo histórico de la humanidad en el individuo. 
Según Hegel:

La tarea de llevar al individuo desde su estado de no formación hasta el saber, había que tomarla en su sentido general o universal, y por tanto había que considerar en su proceso de formación al individuo universal allgemeines Individuum, es decir, el espíritu del mundo. ... Y así, cada individuo recorre también las etapas de formación del espíritu universal. ... y en el curriculum pedagógico reconocemos dibujadas en siluetas la historia de la formación y cultura del mundo (2006, pp. 132133).

La crítica del marxismo a Hegel no consiste en negar el desarrollo del espíritu, sino en exigir una base socioeconómica como condición para sus posibilidades de desarrollo. Incluso, Marx reconoce la analogía entre el desarrollo del individuo y el de la humanidad, cuando alude a la permanencia del valor del arte griego, por cuanto representa la juventud de la humanidad. Con respecto a los griegos, pregunta Marx: “¿Por qué la infancia histórica de la humanidad en el momento más bello de su desarrollo, no debería ejercer un encanto eterno, como una fase que no volverá jamás?"(1971,p. 33)

La analogía entre el desarrollo ontogenético del individuo y la filogénesis de la humanidad tiene sus primeras expresiones en Vico, pero se ha convertido en uno los problemas más importantes de la psicología cognitiva en sus investigaciones sobre el aprendizaje inteligente ${ }^{1}$. El constructivismo explica el aprendizaje inteligente a partir de la acción sobre los objetos, como base sobre la cual se construyen las operaciones físico-matemáticas; de la interacción entre los sujetos, que va conformando los criterios ético-morales de veracidad, justicia y la equidad; de la comunicación, que examina juicios y criterios de objetividad, y, por último, de la acción sobre sí mismo, que va conformando un yo epistémico con estructuras universalizantes y de coordinación de perspectivas.

A partir de las etapas estudiadas por la psicología cognitiva, Habermas propone una reconstrucción del materialismo histórico; este planteamiento conduce a reinterpretar la determinación socioeconómica del marxismo, teniendo en cuenta que el control técnico sobre la naturaleza y las formaciones jurídicas dependen de la

\footnotetext{
${ }^{1}$ En general, el constructivismo de la inteligencia ha sido desarrollado en diferentes temas, entre otros, por Piaget, Kolhberg, la mexicana Emilia Ferreiro, el español Mario Carretero y Vigotsky; de otra parte, se cuenta con la pedagogía activa de John Dewey (constructivismo de uso) y, también, con la pedagogía comprensiva de los mapas conceptuales, en relación con las ciencias hermenéuticas. La conexión entre las investigaciones cognitivas y la historia tiene su mayor desarrollo en las ciencias formales y la física, propuesta en especial por parte de Piaget, así como la relación con los principios morales estudiada por Habermas.
} 
formación de la inteligencia del sujeto y, por tanto, también del desenvolvimiento de la autoconciencia intersubjetiva, lo cual significa un "retorno" a Hegel, pero desde el horizonte de la psicología cognitiva y la comunicación. La reestructuración del materialismo histórico, entonces, debilita la determinación económica y su interpretación a partir de mecanismos de "reflejo" (de la infraestructura en la superestructura jurídico-ideológica), de igual manera que el condicionamiento de clase social; de esta forma, se va tornando necesario apuntar hacia una teoría más abierta, que tome en cuenta la retroacción múltiple entre la instancia socioeconómica y el espíritu, es decir, hacia un socialculturalismo histórico; al mismo tiempo que la declinación de la política comunista conduce hacia la búsqueda de una democracia social y participativa, en la lucha por medio de movimientos sociales: educativos, pluralistas, de diversidad sexual, "indignados", cooperativistas, neo-sindicalistas, ecologistas, pacifistas, indigenistas, estudiantiles y campesinos.

\section{La Filosofía de la Historia Según Hegel}

Para Hegel: "La historia universal es la doma de la violencia desenfrenada con la que se manifiesta la voluntad natural; es la educación de la voluntad para lo universal y en la libertad subjetiva" (2006, p. 202), es decir, es la conciliación entre los derechos universales y los individuales para la conquista de la libertad; no obstante, Hegel amplía el progreso de la historia con la evolución del espíritu. Los saberes del espíritu dependen del desarrollo de la conciencia de sí que tienen los individuos y del espíritu de los pueblos; sin embargo, la finalidad de la historia requiere unos medios de realización como son el Estado y los grandes hombres. Los héroes, los grandes hombres, son hijos de su época y son reconocidos como tales porque saben conducir al pueblo hacia un grado más alto de libertad y de toma de conciencia.

Por Estado, Hegel entiende, de una parte, la conciencia de la libertad, la formación de la subjetividad racional a partir de la cual los seres humanos forjan sus instituciones y sus saberes. De otra parte, el Estado es la "sustancia" social en los aspectos objetivos de las instituciones políticas y las costumbres; así, podríamos decir que para Hegel el Estado objetivo es múltiple: es Estado-político en las instituciones y las leyes positivas, y es Estado-nación a través de la sociedad civil en la comarca, la historia común, la industria, el comercio, las costumbres y la familia. Hegel resume así su concepción del Estado:

Hemos expuesto los dos momentos: el primero, la idea de la libertad, como absoluto fin último; el segundo, el medio de que se vale, el lado 
subjetivo del saber y del querer, con su vida, su movimiento y su actividad. Hemos visto que el Estado es el orden moral y la realidad de la libertad, y, la unidad objetiva de estos dos momentos [...] Hemos conocido la idea, por un lado, en su determinación como la libertad que se conoce y se quiere a sí misma, que se tiene a sí sola por fin: esto es a la vez el simple concepto de razón y también eso que hemos llamado sujeto, la conciencia de sí mismo, el espíritu existente en el mundo (2006, pp. 109-110). ${ }^{2}$

Para Hegel la evolución del espíritu a través de la toma de conciencia de sí mismo, de la autoconciencia y de la libertad se produce por las "contradicciones", luchas o antagonismos categoriales entre los deberes universales en la sociedad y los intereses particulares del individuo. Debido a esta lucha entre lo universal y lo particular: "El progreso no es, pues, una evolución pacífica y sin resistencias; el espíritu no camina pacíficamente a su realización. La historia progresa en el sentido de que las dos partes abandonen su parcialidad, su forma mendaz”(2006, p. 210).

La historia universal se desarrolla en la medida en que se toma conciencia de la universalidad de los derechos a la libertad y se forja una racionalidad en los diferentes aspectos de la cultura intelectual. Para pensar el progreso histórico, Hegel propone una analogía -que tiene su origen en Vico (Horkheimer, 1995, pp. 101118)- entre el desarrollo del espíritu del individuo y el de la especie humana, que pasa por diversas formas del devenir.

La primera forma, la de la infancia, es la del Despotismo Oriental, que presenta una contradicción entre la permanencia de las instituciones y las costumbres que duran milenios, y los caprichos del déspota, que, a su vez, somete a su pueblo a la tradición. En el Despotismo el hombre no obedece libremente, sino que obedece sin más. La ley de la voluntad es para él, la ley del déspota. En esta sociedad solo es libre un individuo: el emperador. "Así, en el edificio suntuoso del poder único, al cual nada escapa y ante el cual nada puede adoptar una forma independiente, va unida a la arbitrariedad indomable" (Hegel, 1989, p. 205).

La segunda forma del espíritu es la juventud de Grecia antigua, que representa la contradicción de la moralidad en la virtud bella de los ciudadanos y la exclusión de la ciudadanía para los esclavos y sirvientes: solo son libres algunos. Así mismo, en Grecia coexisten la tradición y la costumbre con los comienzos de la libertad del sujeto: "Pues la moralidad en la belleza [de la virtud ciudadana] no es la moralidad

${ }^{2}$ Las pseudointerpretaciones que critican a Hegel por endiosar el Estado (de lo cual están llenas las historias de la filosofía) no diferencian entre Estado como institución jurídico-administrativa y el Estado como libertad republicana, pues esta última debe estar por encima de todas las instituciones burocráticas y clericales. 
verdadera, no es la moralidad oriunda de la lucha de la libertad subjetiva que habría nacido de sí misma, sino que sigue siendo aquella libertad subjetiva [particular] y tiene, por tanto, el carácter de la libertad natural" (Hegel, 1989, p. 207). El pueblo griego vive de las costumbres ciudadanas, que no se rigen por principios universales, pero que ya inicia el cuestionamiento de lo simplemente habitual, tanto de la ética y de la política, como del conocimiento.

La tercera forma del espíritu es la manifestación de la etapa de la vida viril en el Imperio romano, que representa la contradicción entre los derechos de la persona jurídica y el Estado político como fin en sí mismo al que sirven los ciudadanos. Los individuos son sacrificados a la dureza de la ley de un Estado que por su formalismo es abstracto. "Los individuos libres son efectivamente sacrificados a la dureza del fin, al cual han de consagrarse en ese servicio para lo abstracto universal" (Hegel, 1989, p. 2075).

La cuarta forma es el imperio espiritual bajo el dominio de la Iglesia. Históricamente comienza con la nueva conciencia de la subjetividad individual aportada por el cristianismo: la igualdad de todos los seres humanos ante Dios, la responsabilidad personal o culpa, y la dignidad humana absoluta. Su contraposición está dada, de una parte, por la interioridad religiosa que desprecia el mundo profano $\mathrm{y}$, de otra, por la profanidad eclesiástica más fiera y salvaje en la acumulación de riquezas y poder.

La quinta forma representa la madurez del pensamiento en la modernidad, que concilia los derechos individuales con los universales. La modernidad se inicia con la herencia griega aportada por los islámicos, que inicialmente la cultivaron y tradujeron; posteriormente, en el Renacimiento, se amplía con la libertad de conciencia, la separación de las iglesias y el Estado favorecida por la Reforma protestante, y culmina con la Revolución francesa según la cual todos los ciudadanos son libres. Para Hegel: "El punto en que la conciliación se verifica, por sí misma es, pues, el saber; aquí es donde la realidad es rehecha y reconstruida. Tal es el fin de la historia universal; que el espíritu dé de sí una naturaleza, un mundo que le sea adecuado [...] creada por el concepto del espíritu, y tenga en esa objetividad la conciencia de su libertad y de su racionalidad subjetivas" (1989, p. 211).

Con la quinta forma del espíritu se llega al "fin de la historia", que no consiste en la detención de la historia misma, sino en la conciliación entre los intereses individuales y los derechos universales. Esta finalidad no puede ser sobrepasada sin renunciar a la forma política republicana instituida por la división de poderes y la participación de la sociedad civil; en consecuencia, para el futuro: "La labor que queda por hacer es precisamente esa: que ese principio se desenvuelva, se elabore, 
que el espíritu llegue a su realidad, llegue a la conciencia de sí mismo en la realidad" (Hegel, 1989, p. 212).

Sin embargo, la forma republicana moderna, defendida por Hegel como el reino de la conciliación y el reconocimiento entre sujetos libres, es considerada por Marx como el interés común de la burguesía, representado en el Estado moderno. Así mismo, la filosofía de la historia del idealismo hegeliano, que expone el desarrollo de la autoconciencia y la razón es, piensan Marx y Engels, una “... inversión que hace caso omiso de las condiciones reales, es lo que permite convertir toda la historia en un proceso de desarrollo de la conciencia" (1976a, p. 73). No obstante, en el marxismo la finalidad de la historia sigue siendo la conquista de la libertad, pero esta no llega a su plenitud en el Estado burgués, sino en el comunismo: "Solamente dentro de la comunidad (con otros tiene todo) tiene el individuo los medios necesarios para desarrollar sus dotes en todos los sentidos; solamente dentro de la comunidad es posible por tanto la libertad personal" (Marx y Engels, 1976a, p. 80).

A pesar de la crítica marxista a Hegel, en la misma filosofía hegeliana se expone la dependencia que la conciencia filosófica tiene de la "sustancia social", es decir, de las condiciones históricamente objetivas, no obstante la evolución del espíritu es la base y la que da forma a los demás aspectos históricos, y al mismo tiempo surge en condiciones históricas orgánicamente específicas. Esta condicionalidad de doble vía se explica por una evolución que procede en círculos, pues "la sustancia social" ofrece las condiciones para el saber y este se realiza produciendo instituciones y formas de vida:

Pero llega un momento en que no solo se filosofa, así, en general, sino en que es una determinada filosofía la que se manifiesta en un pueblo; $y$ esta determinabilidad del punto de vista del pensamiento es la misma determinabilidad que informa todos los demás aspectos históricos del espíritu del pueblo, que guarda la más íntima relación con ellos y constituye su base. [...] bajo la cual surge, con su organización y su forma de gobierno, con su moral y su vida social, sus aptitudes, sus hábitos y su costumbres, con sus intentos y sus trabajos en el arte y en la ciencia, con sus religiones, sus vicisitudes guerreras y sus condiciones externas en general, con la desaparición de los Estados en los que este determinado principio se había hecho valer y con el nacimiento de otros nuevos, en los que se alumbra y desarrolla otro principio superior (Hegel, 1985, p. 55). 


\section{De la Filosofía Idealista Hegeliana al Materialismo Histórico}

En la Introducción a La ideología alemana, Marx presenta una visión general del materialismo histórico, en la cual efectúa un esbozo de la sucesión de los diversos modos de producción de acuerdo con la historia europea. Los modos de producción -o formas de propiedad-que expone son: el tribal, el de la ciudad-estado antigua, el feudal, el capitalista y el comunista ${ }^{3}$. Posteriormente, Marx, en Elementos fundamentales para la crítica de la economía política (1971, pp. 433-479), bajo influencia de Hegel -sin mencionarlo- agrega el modo de producción asiático, caracterizado por la propiedad abstracta del déspota (China, India, Egipto Antiguo, a lo que se podrían agregar las culturas Aztecas e Incas).

La versión del materialismo histórico depende de los diversos textos de Marx y Engels y del modo de producción, que sirve como punto de referencia para la teorización, y también del énfasis que se pone en la cuestión de la toma de partido político. Así, por ejemplo, en La ideología alemana (pp. 3-15) el modo de producción aparece condicionado por varios factores: el recurso del medio geológico; la manera como se produce y el tipo de instrumentos utilizados; la división del trabajo en sus diversas formas (el natural en el trabajo del varón y la mujer; el intelectual y el manual; la división técnica en el interior de la producción y la división social del trabajo en las diferentes tipos de producción como el de la ciudad y campo); las relaciones sociales en la producción en conexión con las organización social en clases y estamentos; el comercio y el consumo, tanto en las naciones como en las relaciones internacionales; el Estado y la política en su trabazón con el orden socioeconómico; la reproducción de la población a través de la familia, la ciudad y la nación, sus instituciones y necesidades socioeconómicas; y por último, la conciencia social que se expresa por medio del lenguaje como conciencia social práctica. La conciencia social también se observa en el comportamiento y en las opiniones que generan "inversiones" ilusorias (idealismos y religiones) o en ideologías que justifican, que "naturalizan" y enmascaran formas de dominación para ofrecer consuelo.

De todos estos factores algunos son más estudiados que otros, especialmente se exploran los que son centrales en el modo de producción capitalista debido al interés político por su transformación. Y, además, hay que contar con la metodología, con el modelo "recurrencial" del materialismo histórico que estudia el pasado a la luz de la organización del presente más desarrollado. De todos estos aspectos, que impiden

${ }^{3}$ Esta denominación es más adecuada que la que aparece en otros textos, en los cuales se caracteriza al primer modo de producción como comunismo primitivo y al siguiente como esclavista. 
una simplificación fácil del materialismo histórico, el que lleva la peor parte es el de la conciencia social. Debido a la preocupación de Marx y Engels por abrir el campo de investigación socioeconómica y también por la oposición contra el idealismo hegeliano, parcialmente dejan a un lado la evolución de la conciencia social (el espíritu), aunque de todos modos se encuentren estudios suyos sobre la historia de la filosofía, de las ciencias y del arte ${ }^{4}$.

En el materialismo histórico se encuentran textos en los que se hace depender la historia de las ideas del orden socioeconómico:

La moral, la religión, la metafísica y cualquier otra ideología y las formas de conciencia que a ellas corresponden pierden, así, la apariencia de su propia sustancialidad. No tienen su propia historia ni su propio desarrollo, sino que los hombres que desarrollan su producción material y su intercambio material cambian también, al cambiar esta realidad, su pensamiento y los productos de su pensamiento. No es la conciencia la que determina la vida, sino la vida la que determina la conciencia [...].Estas abstracciones de por sí, separadas de la historia real, carecen de todo valor [...] no ofrecen en modo alguno, como la filosofía, una receta o un patrón con arreglo al cual puedan aderezarse las épocas históricas (Marx y Engels, 1976a, pp. 14-15).

Sin embargo, más adelante, en el mismo texto, reconocen que esta concepción de la historia, que expone el proceso real de la producción y el intercambio, también estudia la totalidad: las relaciones recíprocas entre las instancias sociales (p. 29). A su vez, Engels, en una famosa carta, matiza las relaciones entre las estructuras:

El desenvolvimiento político, jurídico, filosófico, religioso, literario, artístico, etc., se basa sobre el desarrollo económico. Pero interactúa entre sí y reactúa sobre la base económica. No es que la situación económica sea la causa, y la única activa, mientras todo lo demás es pasivo. Hay, por el contrario, interacciones sobre la base de la necesidad económica, la que en última instancia siempre se abre camino (1973, p. 528).

\footnotetext{
${ }^{4}$ Algunos aspectos de la historia de la ciencia y de la filosofía de la ciencia se encuentran en: Engels, F. Dialéctica de la naturaleza. Trad. Wenceslao Roses. México: Grijalbo, 1961. Sobre la historia de la economía política en: Marx, K. Historia crítica de la teoría de la plusvalía. Buenos Aires: Ed. Cartago, 1956. Sobre el materialismo histórico y el arte existe una compilación de textos: cfr. Marx K. y Engels, F. Cuestiones de arte y literatura (1976 b), Traducción del francés de Jesús López P. Barcelona: Península.
} 
El materialismo histórico ha pasado por varias crisis teóricas - sin contar con las políticas ${ }^{5}$. En los planteamientos teóricos de los modos de producción, de una parte, diversos autores han cuestionado la tesis del desarrollo unilineal sucesivo de los modos de producción, otros han observado las diversas formas como los modos de producción se ramifican o se caracterizan por un desarrollo desigual y combinado ${ }^{6}$; de otra parte, se ha planteado la tesis según la cual el modo de producción no se refiere sino a la estructura socioeconómica y a sus condicionamientos sobre las otras estructuras, y no a la civilización en general; $y$, por último ${ }^{7}$, se han problematizado las relaciones entre estructuras, pues actualmente son muchos los historiadores y filósofos que reconocen la autonomía relativa bajo una causalidad estructural, múltiple y compleja (sobredeterminada) ${ }^{8}$. La causalidad estructural establece un marco de condiciones para las trasformaciones posibles: favorece o dificulta los cambios en los desarrollos de las instancias sociales, pero no puede determinar específicamente los acontecimientos e innovaciones. La estructura no es causa eficiente sino propiciatoria.

\section{La Reconstrucción del Materialismo Histórico, Hacia un Socioculturalismo Histórico}

Para la reconstrucción del materialismo histórico, Habermas se basa en las ciencias reconstructivas, especialmente en la sicogénesis del conocimiento y la moral de Piaget y Kolhberg (1992).

Según Habermas, las teorías reconstructivas exponen competencias y desempeños de reglas (del conocimiento, del juicio moral, etc.) que posibilitan dar cuenta de los criterios de validez; en consecuencia, sirven como apoyo indirecto para la construcción filosófica de marcos sobre la validez cognitiva, normativa y valorativa. Las ciencias reconstructivas, como la sicogénesis del aprendizaje, la

\footnotetext{
${ }^{5}$ La crisis política más fuerte radica en el abandono parcial o total del socialismo de Estado, por cuanto al prescindir de la competencia y de los estímulos no pudo mostrar su superioridad económica sobre el capitalismo, y de otra parte, la dictadura del proletariado desembocó en un totalitarismo burocrático. A su vez, el capitalismo a través de la sociedad de consumo y del "capitalismo popular" que distribuye las utilidades por sistemas accionarios, y a través de diversas formas de política socialdemócrata en la prestación o control de los servicios sociales, compensa, al menos en parte, sus carencias de democracia social. El nuevo límite a la sociedad industrial parece ser ecológico.

${ }^{6}$ Cfr. Godelier, M. (1969). Sobre el modo de producción asiático. Barcelona: Martinez Roca. Melotti, Humberto. (1975). Marx y el tercer mundo. Buenos Aires: Amorrortu. Dhoquois, Guy. (1977). A favor de la historia: Elementos críticos Barcelona: Anagrama .Pelletier, A. y Goblot, J. (1975). Materialismo histórico e historia de las civilizaciones. México, Grijalbo. LONDOÑO R. Carlos Arturo. (1992). "Alternativas a la teoría de la historia”. En: Guerrero R. Amado (Comp.). Ciencia, cultura y mentalidades en la historia de Colombia. Bucaramanga: VIII Congreso Nacional de Historia de Colombia, UIS de 1993.

${ }^{7}$ Cardoso Ciro F.S y Pérez Brignoli (1977). Los métodos de la historia. México, Grijalbo, pp. 369-393. Estos autores se oponen a L. Althusser, quien considera el modo de producción como abarcando la totalidad social. Marx y Engels no se plantearon el problema de las relaciones entre los modos de producción y las civilizaciones.
} 
pragmática formal del lenguaje y la teoría de la argumentación, estudian la formación de la inteligencia y la comunicación dirigida al entendimiento.

La teoría sicogenética de Piaget abarca, al menos, cinco grandes modalidades del aprendizaje: las operaciones sobre los objetos que, a partir de la coordinación de la acción, posibilitan las abstracciones físico-matemáticas; la interacción social, que genera los criterios morales; la descentración de la comunicación, que capacita para el análisis de los diálogos, la crítica, el análisis y la síntesis; el aprendizaje en la participación democrática, y el simbolismo figurativo, que coordina la fantasía y las juegos.

La teoría sicogenética piagetiana ha sido ampliada con estudios sobre el aprendizaje ontogenético de los órdenes de la temporalidad histórica, las narraciones, las decisiones, las organizaciones sociales (Carretero, Pozo y Asencio, 1989), la escritura (Ferreiro, 1999), etc., tal como lo han iniciado algunos autores neopiagetianos. Estos nuevos estudios abren la perspectiva a nuevas competencias sobre el conocimiento social, sin reducirlo a la interacción moral (como lo hace Habermas). Además, se requiere considerar el aprendizaje comprensivo ${ }^{9}$ holísticoestructural de las "concepciones del mundo", estudiadas por las ciencias hermenéuticas, cuya autocrítica está dada por la filosofía.

En la sicogénesis, la conciencia de sí no resulta de una intuición inmediata, sino de un proceso que disocia los contenidos de conciencia y se genera por la diferencia que se establece entre el sujeto y el objeto (el yo y el no-yo) y entre el punto de vista propio y el de los demás. En las primeras etapas de la inteligencia, el yo se confunde con el universo; la conciencia del yo es opaca, y todo fenómeno natural es interpretado de modo sicomórfico, o pseudoexplicado, como si fuera un siquismo (animismo, artificialismo, finalismo, magia). El yo es el producto de una escisión con respecto a los objetos naturales y a las opiniones colectivamente establecidas. En la descentración, el siquismo del sujeto deja de ser el centro de la interpretación de la naturaleza y, en su lugar, se va conformando el yo racional o epistémico que considera que la naturaleza funciona con mecanismos físico-matemáticos y regularidades orgánicas. El proceso de la descentración del sujeto, aplicado a las teorías históricas, permite diferenciar las representaciones egocéntricas del mundo, divididas en formas antropomórficas o sicomórficas sobre la naturaleza, y fisiomórficas (si se nos permite este neologismo) sobre la sociedad, según la cual las costumbres de la propia cultura son consideradas naturales. En la medida en que se racionaliza la naturaleza y se comprende históricamente la sociedad se conforman, a su vez, representaciones descentradas del mundo.

${ }^{9}$ Para el aprendizaje comprensivo, cfr. AusubeL, D. Novak, J.D. y Hanesian H. (1983). Psicología educativa. México: Trillas. 
En la teoría de Piaget, en la comunicación como forma de interacción cognitiva, se pasa de su manifestación egocéntrica a la descentrada (Piaget, 1972). La comunicación egocéntrica habla para sí misma: no se interesa por el análisis, es decir, por la división del discurso en sus partes, ni por la argumentación, las pruebas o la crítica. El pensamiento egocéntrico es básicamente sincrético, es decir, se conforma como una globalidad más o menos vaga y generalizante; comprende más como pensamiento "intuitivo-figurativo" por el uso de esquemas de analogías, que por procedimientos de tipo deductivo o argumentativo. Se afirma sin necesidad de justificar, sin preocupación por la claridad e inteligibilidad; se salta etapas en la narración y en la argumentación. La inteligencia comunicativa, por el contrario, es más semánticamente deductiva, intenta establecer enlaces entre las proposiciones (si, entonces...; dado que, luego...); insiste más en las pruebas; elimina los esquemas de analogía - hasta donde es posible- para reemplazarlos por conceptos propiamente dichos, $\mathrm{y}$, por último, prescinde de los juicios personales de valor para referirse a los que se comparten intersubjetivamente de modo razonable.

La comunicación egocéntrica se aferra a la verdad, considerándola absoluta; prefiere seguir a los otros por imitación, antes que ejercitar el pensamiento propio; sin embargo, se atiene al propio punto de vista, sin confrontarlo con el de los demás. El pensamiento egocéntrico se comunica bajo la indiferenciación entre lo individual y lo social, es decir, adopta simplemente las opiniones y el comportamiento social y proyecta en el mundo su fabulación, de tal manera que le es difícil diferenciar la vida intersubjetiva de sus propias fantasías.

En relación con el pensamiento egocéntrico, Piaget estudia también el pensamiento autístico $^{10}$-según el término acuñado por el psicoanalista Bleuler-, que se puede denominar también mitopoético, el cual, en sus expresiones básicas, manifiesta espontáneamente imágenes ligadas a las demandas y a las funciones orgánicas; es predominantemente asociativo y corresponde a la representación que Lacan denomina: lo imaginario; es un pensamiento subconsciente: los fines que persigue, las pulsiones y demandas vitales no están explícitas en la conciencia, no tiende a buscar verdades, sino a expresar temores, a satisfacer deseos e ilusiones: permanece subjetivizado; procede, especialmente, por imágenes y figuras retóricas del lenguaje; se comunica por vías indirectas, evocando sus intenciones subconscientes por medio de la recreación de sueños, mitos, ritos, leyendas y metáforas que le sirven de guía.

El pensamiento mitopoético no es dirigido racionalmente, sino por medio de símbolos figurativos, como, por ejemplo, tomando un caso bien conocido, el del

${ }^{10}$ El pensamiento autístico, en cuanto una forma de pensar con figuras simbólicas ligadas a las demandas orgánicas, no tiene relación con la patología biológica del autismo. 
agua: para la inteligencia, es un líquido que se puede emplear en unos usos de acuerdo con sus propiedades regulares; para el pensamiento autístico, por el contrario, representa la fecundación, la micción y el nacimiento; en su expresión religiosa aparecen los ritos de purificación y el bautismo.

El pensamiento inteligente es dirigido, se propone fines para actuar, se comunica de modo coherente, pretendiendo la verdad, la inteligibilidad y corrigiendo los errores a medida que asimila y se acomoda a la experiencia. En la historia, el pensamiento egocéntrico y autístico se manifiesta como mitopoético, y se expresa en muchas facetas de la cultura. En la modernidad se incrementa la diferenciación entre los campos del saber racionalmente sustentados y la representación figurativa, de tal manera que el pensamiento mitopoético se transforma y se recrea en el arte y la religión.

La descentración del sujeto se genera también en la moral. En la formación de los criterios morales, la descentración del sujeto se efectúa por el paso del pensamiento heterónomo, en el cual el sujeto se somete simplemente al juicio de los otros, a la elaboración de unos criterios autónomos a partir de juicios racionales. En la moral heterónoma, las reglas de comportamiento se interpretan como invariables o eternas $\mathrm{y}$, en consecuencia, existe una resistencia a su cambio. En la transición hacia la moral autónoma, las reglas se conciben como relativas, es decir, se consideran susceptibles de transformación, y se comprende que se constituyen por acuerdos de cooperación.

La moral heterónoma se basa en el respeto unilateral a la autoridad; acepta la sumisión a las reglas coercitivas de la sociedad ejercidas por la presión exterior. Las reglas se consideran un conjunto de consignas establecidas tradicionalmente, un producto social cristalizado, y se conciben análogas a la ley natural: las costumbres se naturalizan. Curiosamente, como en un juego de espejos, las normas sociales son entendidas como leyes del universo, y este se rige por normas análogas a las sociales. Por ejemplo, el niño cree que es un deber del sol salir todas las mañanas, y en las civilizaciones arcaicas la estabilidad del universo depende de los ritos y sacrificios. Los estudios piagetianos equivalen a las investigaciones antropológicas que han mostrado que, en culturas arcaicas, las costumbres sociales se naturalizan de modo fisiomórfico, y, a la inversa, la naturaleza se "socializa" de manera antropomórfica.

Con el proceso de socialización ontogenético de los individuos y con la diferenciación social que se va produciendo en la historia cesa el dominio del conformismo obligatorio y se pasa a la normatividad, entendida como cooperación social autónoma, por medio del respeto mutuo; la regla se convierte en racional, se interioriza y se somete al control recíproco entre individuos considerados iguales. 
La cooperación se presenta como un término límite o como equilibrio ideal entre el ego y el alter. En la medida en que las sociedades evolucionan, dejan cada vez mayor margen para la libre discusión entre individuos; de este modo, la historia se puede concebir como una evolución de estadios de conciencia que rige comportamientos que se van tornando recíprocos. La autonomía y la heteronomía están en correlación con la morfología de las coacciones de los grupos, pues la cooperación nunca es pura, ya que depende de la presión social para la aceptación o modificación de las normas. La cooperación, el respeto mutuo, no se realizan nunca de modo total; se van constituyendo como formas de equilibrio, limitadas e ideales, o como compensaciones entre el yo y los otros. Siempre existe la presión de las reglas y de las opiniones, ejercida por la coacción social. Solo se someten a juicio recíproco un conjunto limitado de normas y valores, pero, una vez constituida la etapa del respeto recíproco, tiende a generalizarse al conjunto de la vida social y la normatividad se universaliza.

La evolución que Piaget presenta en las etapas de la moral heterónoma y autónoma se corresponden, respectivamente, con la transformación de las siguientes categorías: la vigencia social, que cambia hacia la racionalidad normativa; el paso de la obligación por simple obediencia, que deviene posteriormente en cooperación, y el respeto unilateral, que se modifica en el respeto recíproco del reconocimiento de los derechos. Esta evolución de la moral hacia la autonomía adquiere su límite en la conformación de grupos cerrados. En el consentimiento general en el interior de grupos, como el que se presente entre pilluelos que se organizan para jugar "malas pasadas" a las otras gentes, o, como en el ejemplo que ofrece Marx sobre las sociedades invasoras del pillaje, la cooperación se circunscribe al grupo mismo, en el que se cumplen ciertos códigos de honor, pero en el que las reglas de respeto recíproco no están universalizadas. El niño, por ejemplo, puede practicar la reciprocidad como en una especie de Ley del Talión o, bien, en la forma de la simpatía; en estos casos, la reciprocidad es de hecho, no de derecho o ideal, pero esta forma vigente de la reciprocidad contribuye a la universalización de las normas hacia formas más refinadas de justicia. No es lo mismo practicar la reciprocidad por la simpatía que se siente hacia otras personas, que ejercerla porque se reconocen los derechos de los otros. Piaget expone, además, la diferencia entre el ejercicio de las reglas y la conciencia lúcida de las mismas. Es necesario que la regla habitual se vea contrarrestada por un conflicto que provoque la búsqueda de nuevas reglas; esta condición para la evolución moral, desde el punto de vista sociocultural, implicaría la necesidad de los conflictos que se presentan entre las colectividades históricas (de clase o estamento, o entre instituciones, nacionalidades e ideologías).

En la moral heterónoma, la justicia retributiva de sanciones considera los castigos una expiación o una compensación de sufrimiento proporcional a las faltas. La 
justicia distributiva se entiende como igualdad de todos - dentro del mismo grupoindependientemente de las condiciones; así, los niños creen en la igualdad de trato, sin considerar las diferencias de edad. Con el paso a la moral autónoma, la justicia retributiva cambia hacia la sanción por reciprocidad: ya no se busca la expiación, sino la compensación por las consecuencias de las faltas, como en el caso del padre que se niega a hacerle un favor al niño, ya que él se ha negado, a su vez, a cumplir con los deberes. La justicia distributiva cambia del igualitarismo homogéneo de la moral heterónoma hacia la equidad de la moral autónoma; se deja de lado la igualdad estricta, en favor de una justicia superior. Así, por ejemplo, el niño mayor acepta cierta condescendencia con los más pequeños. La moral heterónoma juzga las faltas en términos de las consecuencias objetivas, independientemente de las intenciones, según la cantidad de perjuicios. La moral autónoma, por el contrario, juzga las faltas a partir de las intenciones; así, por ejemplo, para la moral heterónoma es más grave romper diez vasos que uno solo; para la moral autónoma, la falta depende de si la acción se realiza por accidente o con premeditación (lo que para Hegel es la formación de la moralidad de acuerdo con la decisión libre en las repúblicas.)

En la teoría de Piaget, existe cierto paralelismo entre la evolución de las reglas cognitivas -que permiten objetivar los objetos-y la reciprocidad moral, de tal manera que el egocentrismo, con respecto al mundo natural y social, son dos formas del mismo egocentrismo. El hombre aprende a disociar el yo epistémico del mundo externo y de la presión social, y, así, se torna capaz de organizar en términos físicomatemáticos el mundo natural y a ejercitar la discusión recíproca.

Sobre la base de las teorías del aprendizaje intelectivo, Habermas (1983, pp. 131180) propone una reconstrucción del materialismo histórico. La versión clásica del materialismo histórico ha propuesto un modelo basado en el proceso evolutivo endógeno de las fuerzas productivas, que se corresponden con las relaciones sociales de producción en cuanto a la propiedad de los medios de producción. En la versión estructuralista, el modo de producción entra en desequilibrio ("en contradicciones") cuando las fuerzas productivas exceden las relaciones sociales de producción y conforman una incongruencia estructural; esta conduce a la transformación de las relaciones sociales existentes. Este modelo, según Habermas, no explica de dónde surgen las innovaciones evolutivas, pues no considera los procesos de aprendizaje desde el punto de vista cognitivo físico-matemático (en la aplicación técnico-cognitiva a las fuerzas productivas), ni como relaciones sociales regidas por la sicogénesis práctico moral y comunicativa. De acuerdo con Kohlberg, dice Habermas que un nuevo modelo de desarrollo evolutivo debe involucrar las teorías del aprendizaje en las tres etapas del aprendizaje moral y de la comunicación simbólica. 
En la etapa preconvencional (heterónoma), los sujetos únicamente valoran las consecuencias de la acción, sin considerar las intenciones, lo cual significa que se les imputa igual responsabilidad por las acciones que se realizan con intención o que se efectúan sin ella. En cuanto al juicio sobre la moralidad, se considera justo lo que corresponde al interés particular, y los conflictos se dirimen con el criterio de la venganza y del castigo, entendido como una expiación según el perjuicio causado, como una especie de ley pre-talión (ojo por ojo, independientemente de las intenciones). Desde el punto de vista de la comunicación simbólica no existe separación entre los motivos para una acción (por qué se hace) y la acción misma.

En la etapa convencional se juzgan las cuestiones morales de acuerdo con el acatamiento de las costumbres, las expectativas y las normas vigentes que convienen al "orden social establecido", se evalúa si se ajustan a los usos de los roles o a lo que la sociedad considera "bueno"; por esta razón, el juicio moral es proclive a la intolerancia y se muestra a favor de la homogeneidad de la comunidad. No obstante, en este juicio moral se diferencia entre las acciones y las intenciones: se aprecian los motivos de la acción, independientemente de las consecuencias o de lo que resulta en los hechos. Desde el punto de vista de la comunicación simbólica se pueden intercambiar perspectivas de participación y de acción con otros participantes, de tal manera que mutuamente se delimitan firmemente los roles y se separan las normas de las acciones, pero no hay exigencias de justificación racional.

En la etapa posconvencional (autónoma) se adquiere la capacidad de juzgar las normas de la sociedad sobre la base de principios racionales de validez universal, y, por esta misma razón, los sistemas normativos pierden su calidad de naturales. Desde el punto de vista de la comunicación se toma en cuenta la argumentación de la validez. Las afirmaciones se consideran de modo hipotético y tienen que ser fundadas, de igual modo, las normas se diferencian de los principios y quedan sujetas al juicio sobre su justicia a partir estos principios.

Las etapas de la acción práctico-moral le permiten a Habermas elaborar cuatro grandes periodos del desarrollo de la humanidad; esta división de la historia por etapas de sociedad y civilización que corresponden a niveles de aprendizaje cognitivo, práctico-moral y comunicativo permite incluir diversos modos de producción en una misma civilización. El desarrollo se efectúa como respuesta ante los retos por medio de resolución de problemas que producen nuevas instituciones:

a) Las sociedades del neolítico - modos de producción tribales, entre otros, que son comunitarios- se rigen por una acción moralmente convencional; los mitos y los ritos están ligados a los sistemas de acción (recolección, caza, reproducción, etc.), pero la regulación de los conflictos se realiza de modo preconvencional, según el interés particular y la venganza. 
b) Las primeras civilizaciones arcaicas ${ }^{11}-$ modos de producción asiáticos, el "feudalismo" arcaico oriental- se rigen por una moral convencional, pero ligada al jefe, al representante de la dominación. Los mitos se separan de los sistemas de acción y adoptan la forma pseudolegitimadora del titular de la dominación, que es al mismo tiempo ejecutivo, legislativo y judicial. Se inician las primeras transformaciones de la responsabilidad colectiva a la individual y el paso de la venganza a la pena.

c) Las civilizaciones desarrolladas - modos de producción de las ciudades-Estado y del feudalismo- se rigen por una moral convencional independiente del titular de la dominación; pero en la comunicación se inicia la ruptura entre el pensamiento mítico y las costumbres admitidas a través de concepciones racionalistas del conocimiento y de una moral parcialmente posconvencional.

d) La civilización moderna - modo de producción capitalista- (y el capitalismo de Estado) lleva a cabo la evolución (inacabada) en la que todas las esferas de la integración social valorativa, la moral, en cuanto normas legítimas, y el derecho entran en la etapa posconvencional. De otra parte, se diferencian los sistemas estratégicos de la producción y del Estado. Comienza la organización política en la democracia formal con la universalización del voto y la división de poderes. La ética se concibe con base en principios de convivencia civil, independiente de la moral convencional de las tradiciones y religiones, también se separan de modo estricto el derecho, considerado de modo formal, universal y racionalizado, de la moral privada. El conocimiento científico se separa de las opiniones religiosas y se produce lo que Max Weber denomina "el desencantamiento del mundo".

La reconstrucción del materialismo histórico debe considerar las instancias estructurales socioeconómicas y jurídico-políticas y la conciencia social, como estructuras profundas, dado que corresponden, respectivamente, a las innovaciones del aprendizaje cognoscitivo, práctico-moral y comunicativo; en este sentido, las estructuras intelectuales no son simplemente "reflejos" derivados de una infraestructura socioeconómica, no obstante, imponen diversas condiciones, recursos y límites a otras estructuras, sin que pueda agotar las condiciones necesarias para las innovaciones y para las obras socioculturales. Cada una de las estructuras desempeña múltiples funciones:

La instancia socioeconómica plantea retos a los que se responde con innovaciones de acuerdo con el aprendizaje técnico-cognitivo en la producción y la circulación,

${ }^{11}$ El término de civilizaciones arcaicas no es de Habermas sino de Piaget. Cfr. Piaget, J. $\left({ }^{1975}\right)$. Introducción a la epistemología genética: ${ }^{2}$ El pensamiento físico. Buenos Aires: Paidós. 
constituye recursos de acuerdo con las condiciones ecológicas, implica diversas formas de división del trabajo, condiciona el consumo, incide en las jerarquías de los grupos dominantes -de clase, estamentos, colectividades y estatus-, condiciona las formas de propiedad y posesión, posibilita las relaciones comerciales y culturales entre naciones, incide en el crecimiento y nivel de vida de las poblaciones, circunscribe límites y condiciones para el desenvolvimiento de las otras instancias sociales, sugiere modelos de interpretación social, y ocupa un papel formativo del entendimiento.

La instancia jurídico-política condiciona las formas de poder gubernamental y estatal de acuerdo con la evolución de las estructuras práctico-morales; organiza planes de acción estratégica administrativa militar y delimita territorios; reglamenta las formas socioeconómicas de intercambio y de movilidad de poblaciones; ejerce formas de coacción y cohesión sobre los diversos grupos sociales; regula y orienta las instituciones (familiares, religiosas, educativas, de salud, etc.); reglamenta las comunicaciones, promueve tradiciones y excluye discursos; controla y favorece motivaciones socioculturales; ejerce cohesiones y normas legítimas, y genera formas de socialización de los individuos.

La conciencia social comunicativa se desarrolla de acuerdo con los aprendizajes técnico-cognitivo, cognitivo-social (ciencias), práctico-moral (disciplinas éticojurídicas) y estético-religioso, englobados en representaciones del mundo (egocéntricas o descentradas). Desde la teoría piagetiana de la evolución de los criterios morales, aparece la diferencia entre la conciencia de las normas y la práctica de estas, pues lo que se dice no corresponde con lo que se hace; además, la práctica de las normas no implica, necesariamente, la conciencia de ellas, y la reciprocidad puede quedar reducida a grupos cerrados (Cfr. Piaget, 1971). Por esta razón, la conciencia social moral, a su vez, puede ser distorsionada a través de pseudojustificaciones por medio de ideologías de dominación que limitan la universalización a grupos cerrados que promueven una falsa conciencia acerca de sus privilegios. La reconstrucción del materialismo histórico debe considerar las ideologías de dominación que "ocultan" o impiden acceder a las competencias práctico-morales universalistas. Sin embargo, cuando entran en crisis las formas convencionales acostumbradas, la conciencia social también es cuestionada por la crítica autorreflexiva de las ciencias hermenéuticas y la filosofía.

Las reconstrucciones abarcan sistemas anónimos de reglas, los cuales pueden ser estudiados en un número indefinido de sujetos que adquieren estadios de competencia. La autocrítica, por el contrario, versa sobre la formación de la identidad del sujeto en las tradiciones culturales que examinan sus propios presupuestos. En el momento en que las situaciones históricas han hecho crisis y se 
han roto las formas habituales de la conciencia social convencional se torna posible la autocrítica ${ }^{12}$.

Históricamente, la adquisición de nuevas competencias ha sido constituida por la génesis histórica de la crítica a las tradiciones culturales, como en el caso de los filósofos de la Ilustración con respecto a la Revolución francesa -y en general las revoluciones burguesas e independentistas-; de allí surge, especialmente, la moral posconvencional de la modernidad y la racionalidad moderna; no obstante, la cultura intelectual moderna fue favorecida por los cambios que se estaban llevando a cabo en la técnica de producción y comercio, en la formación de la familia pequeño burguesa, en la nueva jerarquía de las clases sociales y en la formación de la individualidad moderna.

Las diversas formas de cooperación y los conflictos constituyen presiones para la reorganización y cruzan todas las instancias sociales, que se condensan en "la sustancia social": en instituciones socioeconómicas, jurídico-políticas y de reproducción de la conciencia social. Las instancias sociales se desarrollan en diversos niveles: en estructuras de profundidad (reglas fundamentales de la organización social), de superficie (desenvolvimientos y ajustes de las reglas) y en desempeños (los acontecimientos efectuados por agentes sociales). El cambio estructural se produce por medio del funcionamiento de las estructuras de aprendizaje, en la medida en que se producen desequilibrios ("contradicciones") a través de los procesos de: interiorización/realización (Vigotsky), asimilación/acomodación (Piaget), reto/respuesta (Toynbee) y bajo condiciones diversas de autonomía y dependencia de las diversas estructuras. Así mismo, corresponden a distintas modalidades de la temporalidad de corta y larga duración (Braudel), y de asincronía entre las distintas instancias y factores sociales (Trotsky). En Grecia, por ejemplo, la culminación de la filosofía tiene un desfase de aproximadamente un siglo con respecto a la política.

La reconstrucción del materialismo histórico expone una lógica genéticoestructural que remite a una dinámica histórica: no basta la simple lógica de la historia, pues carece de contenido en cuanto a los conjuntos ideales del desarrollo histórico que permiten especificar la pluralidad de las formaciones socioculturales. Los conjuntos ideales de la dinámica histórica en las formaciones sociales, como estructuras de superficie y desempeños de agentes y grupos, a su vez, retroactúan dentro de ciertos límites (dependiendo de las "grietas" e incongruencias en la organización social), transformando las estructuras. Debido a la diversidad y

${ }^{12}$ A partir de estas limitaciones que Piaget plantea para la reciprocidad, se torna ineludible, además de la formación de competencias, la autocrítica cultural. Habermas tiende a considerar que las teorías reconstructivas sustituyen la crítica filosófica, asunto que él mismo ha observado en apuntes de autocrítica (Habermas, 1988, p. 334). 
particularidad de la historia en múltiples formaciones sociales, la lógica de la historia debe ser complementada con un socioculturalismo histórico que logre exponer la multiplicidad socioeconómica y sociocultural.

La reconstrucción del materialismo histórico intentada por Habermas representa un "retorno" a la tesis hegeliana, que ya había sido iniciado por Piaget en sus libros sobre epistemología histórica de la ciencia. Hegel concibe el desarrollo histórico bajo la teleología de la razón y como conquista de la libertad, solo que esta vez se reconstruye sobre la base de las teorías del aprendizaje inteligente. Sin embargo, los antropólogos -y algunos filósofos posmodernos- han mostrado cómo en la colonización y aculturación forzada de otros pueblos se ha utilizado la teleología de la historia como una ideología de dominación (Londoño, 1995, pp. 11-22). De otra parte, la antropología ha mostrado unas formas de convivencia comunitaria en los pueblos primitivos, aunque la reciprocidad esté limitada al contexto social (que Durkheim reduce a la "solidaridad mecánica"); estas formas de convivencia se han perdido en los pueblos modernos que viven en grandes ciudades de individuos anónimos.

En otra perspectiva, la Teoría Crítica de la Sociedad (Adorno, Horkheimer, Fromm) ha cuestionado la modernidad, por cuanto ha dado lugar a fenómenos como el totalitarismo y a la supremacía de la razón instrumental, que reduce toda la racionalidad a la coordinación de medios y fines con pretensiones de éxito, subordinando toda otra racionalidad. El psicoanálisis social ha mostrado, además, que es necesario contar con la "motivación social": pues con la autonomía del yo, también aparece la angustia ante la pérdida de las tradiciones y la inseguridad ante la carencia de un "padre social". Al parecer, esta falta se compensa con un poder autoritario que absorbe el mundo de la vida y se amalgama con el fanatismo de la supremacía de la razón instrumental, que se sobrepone a toda otra racionalidad y circunscribe a grupos cerrados la legitimidad práctico-moral.

Estas situaciones, al menos en principio, conducen a considerar diferentes formas del aprendizaje y del desaprendizaje, de tal manera que, paradójicamente, la humanidad evoluciona en unos sentidos e involuciona en otros. La razón occidental, por este aspecto, también realiza una selección de sus direcciones evolutivas, que frecuentemente se han presentado como absolutas. Es indudable el progreso en las estructuras de la inteligencia cognitiva, moral y comunicativa, pero este, a su vez, se puede producir conjuntamente con un retroceso desde la óptica del dominio unilateral de la razón instrumental por parte de la tecnocracia, de la pérdida de la convivencia comunitaria por el individualismo capitalista, del ahogo de la conciencia de la subjetividad como consecuencia del cientificismo y el consumismo, y del opacamiento del "sentido vital", que Nietzsche caracterizaba como una de las formas de nihilismo. 


\section{Conclusiones}

La teoría de Hegel ha sido cuestionada por cuanto se la considera "especulativa", y el materialismo histórico ha sido señalado como pseudociencia por el neopositivismo. Del cuestionamiento a las grandes teorías de la historia no quedan, entonces, sino estudios cada vez más parciales, más circunscritos, más pequeños y más especializados; esta especialización no es errada, pero sí es parcial. Todas las ciencias y disciplinas requieren de lo universal y de lo particular, de la totalidad y de lo parcial. Para el desarrollo del espíritu se requiere un movimiento que conduzca de una categoría a su contraria y viceversa (Londoño, 1983, pp. 32-49).

Uno de los grandes problemas del materialismo histórico a nivel académico ha sido su gran tendencia al encerramiento y al dogmatismo, debido a las polaridades políticas nacionales e internacionales; sin embargo, después de la caída del "Muro de Berlín" se ha producido una "desbandada" de los estudios históricos que han ido perdiendo buena parte de sus referentes teóricos y que se refugian en descripciones cada vez más especializadas, perdiendo así la visión de totalidad y su anclaje socioeconómico.

En la psicología cognitiva, como lo han mostrado tanto Piaget como Habermas, existe, sin embargo, una base científica, es decir, teórico-empírica, que permite una revisión de los planteamientos clásicos con el fín de actualizarlos y enriquecerlos. De todas maneras, se requiere aprender de modo inteligente para realizar innovaciones técnicas, para recrear la ciencia, para forjar nuevas legislaciones y para reconstruir también la filosofía. Los estudios sobre la inteligencia permiten comprender los grandes periodos estructurales del desarrollo en el individuo, los que, a su vez, sirven de base para comprender también la historia de la humanidad, considerando, por supuesto, las grandes diferencias que puede haber entre el desenvolvimiento individual y el histórico.

En lo fundamental, el aporte de la psicología cognitiva es mostrar una nueva forma de la teleología histórica sobre la base del aprendizaje: un estructuralismo genético. Esto no significa que necesariamente exista un recorrido predeterminado y lineal, es más bien un conjunto de competencias posibles, inmanentes a toda cultura humana. La ciencia, el derecho universal y la filosofía no son solo patrimonio de la cultura occidental, existen como un potencial de aprendizaje para todo ser humano. De hecho, así aparece en la actualidad con la escolaridad a nivel mundial. Los diferentes estadios del aprendizaje, aunque pueden aparecer en germen en todas las culturas, requieren, no obstante, unas condiciones socioeconómicas y políticas que los favorezcan y unos conflictos socioculturales que los "desencadenen". 
Con la psicología cognitiva se abre una nueva posibilidad para sustentar investigaciones históricas a partir del desarrollo del aprendizaje inteligente en muy diversas instancias sociales. Se aprende a universalizar conceptos y principios, tanto en las ciencias como en la ética y en el derecho, a partir de conflictos históricos. Se aprende a geometrizar en la pintura y la escultura, así como en la escritura y en la coherencia narrativa y argumentativa. La psicología cognitiva, al menos en principio, permite comprender cómo se van separando los diferentes campos de la cultura: las ciencias, el derecho, las artes y las creencias. La psicología cognitiva también representa una nueva manera de entender los fenómenos religiosos, como formas egocéntricas: antropomórficas y sicomórficas, y no solo como una posible ideología de dominación, que es la forma popularizada de interpretarlos desde el marxismo (habría que contar además con formas autocéntricas de la ilusión, estudiadas por el sicoanálisis). No obstante, en estos estudios no bastan el constructivismo y el sicoanálisis, ya que las religiones aportan cierta sabiduría, como la serenidad, el autocontrol, la contemplación y la compasión, cuestionadas por la filosofía.

El desarrollo de la inteligencia ofrece unas claves genético-estructurales del aprendizaje; no obstante, también hay un aprendizaje de la razón que se genera por el recorrido autocrítico de la historia de la filosofía, estudiado por las ciencias hermenéuticas. El recorrido histórico de la cultura intelectual, de todas maneras, presupone condiciones sociales que plantean retos, límites, recursos, fuerzas a favor $\mathrm{y}$ en contra, y ciclos de interiorización y exteriorización, de asimilación y acomodación, de equilibrios y desestabilizaciones, además de antinomias y paradojas. No existe la causa primera, sino un entramado de estructuras y acontecimientos que favorecen u obstaculizan el desarrollo de la inteligencia y de la razón.

A pesar del escepticismo acerca de una teleología de la historia, de todas maneras las políticas democráticas propugnan nuevas formas de libertad y de educación, es decir, por el desarrollo del espíritu, aunque este también cuenta con los nuevos medios de la tecnología. También, a pesar de las crisis totalitarias, ya sea de tipo militar, burocrático o eclesiástico que intentan eliminar la libertad de pensamiento y de formas diversas de vida, de nuevo la lucha por la libertad y el desarrollo de la cultura intelectual renace una y otra vez, creando ramificaciones y nuevos frutos. Kant planteaba que la lucha por la libertad siempre genera de modo permanente un entusiasmo (que etimológicamente significa estar en un dios), aunque en algunos momentos se fracase, como pudo haber fracasado la Revolución francesa.

El escepticismo sobre la teleología de la historia se debe también a un mal entendimiento del asunto, es decir, se debe a pseudointerpretaciones. Propugnar un 
futuro con condiciones que favorezcan el crecimiento humano no es una profecía, sino una defensa, una lucha, un esfuerzo en favor del desarrollo del espíritu, pues de lo que se trata, en último término, es de la sustentación de un ideal ético y educativo, no solo en cuanto a las formas constitucionales de las repúblicas, que actualmente involucran los derechos humanos; se trata, como dice Hegel, de un equilibrio entre los derechos y deberes universales, y los derechos y deberes de los particulares, incluidas las relaciones entre los Estados. Este proceso no es fácil ni pasivamente pacífico, involucra conflictos y dificultades, pero en el recorrido se aprende.

\section{Referencias}

Althusser, L. (1967). La revolución teórica de Marx. Buenos Aires: Siglo XXI. Ausubel, D.; Novak, J.D. y Hanesian H. (1983). Psicología educativa. México: Trillas.

Cardoso, Ciro F.S. y Pérez Brignoli, H. (1977). Los métodos de la historia. México: Grijalbo.

Carretero, M, Pozo, J. I., y Asensio, M. (Comps.), (1989). La enseñanza de las ciencias sociales. Madrid: Visor.

Dhoquois, G. (1977). A favor de la historia: Elementos críticos. Barcelona: Anagrama.

Ferreiro, E. (1999). Cultura escrita y educación: Conversaciones con Emilia Ferreiro, Daniel Goldin y Rosa María Torres. México: Fondo de Cultura Económica.

Engels, F. (1961). Dialéctica de la naturaleza. Trad. Wenceslao Roses. México: Grijalbo.

Engels, F. (1973). "De Engels a H. Starkenburg. Londres, 25 de enero de 1894”. En: Correspondencia completa de C. Marx-F. Engels. T. II. Bogotá: Editor Rojo.

Godelier, M. (1969). Sobre el modo de producción asiático. Barcelona: Martínez Roca.

Habermas, J. (1983) "La reconstrucción del materialismo histórico". En: La reconstrucción del materialismo histórico. Madrid: Taurus, pp. 131-180.

Habermas, J. (1988). Conocimiento e interés. Trad. Manuel Jiménez y otros, Madrid: Taurus.

Hegel, G.W.F. (1985). "Introducción a la historia de la filosofía". En: Lecciones sobre historia de la filosofía. T. I. México: Fondo de Cultura Económica.Hegel, G. W. F. (1989). Lecciones sobre la filosofía de la historia universal. Trad. José Gaos. Madrid: Alianza. 
Hegel, G.W.F. (2006). Fenomenología del espíritu. Trad. Manuel Jiménez Redondo. Valencia: Pre-textos.

Horkheimer, M. (1995). "Vico y la mitología". En: Historia, metafísica y escepticismo. Barcelona: Altaya.

Kohlberg, L. (1992). Psicología del desarrollo moral. Bilbao: Descleé de Brouver.

Londoño R. C. A. (1983). “El método teórico y la investigación hipotético deductiva en el materialismo histórico”. En: Asia y África en América Latina. Memorias del Segundo Congreso de la Asociación Latinoamericana de Estudios afroasiáticos. ALADAA, Paipa, 6-10 abril, 1981. Tunja, Colombia: Universidad Pedagógica y Tecnológica de Colombia, La Rana y el Águila.

Londoño R., C. A. (1992). "Alternativas a la teoría de la historia”. En: Guerrero R., A. (Comp.): Ciencia, cultura y mentalidades en la historia de Colombia. Bucaramanga: VIII Congreso Nacional de Historia de Colombia, UIS.

Londoño R., C. A. (1995). "La razón trágica de la humanidad”. Rev. Couniversitarios. N. ${ }^{\circ}$ 1, junio, Tunja: UPTC, pp. 11-22.

Marx, K. (1956). Historia crítica de la teoría de la plusvalía. Buenos Aires: Ed. Cartago.

Marx, K. (1971). Elementos fundamentales para la crítica de la economía política. Trad. Pedro Scaron, Madrid: Siglo Veintiuno.

Marx, K. y Engels, F. (1976a). La ideología alemana. Trad. Wenceslao Roses. Medellín: Ed. Pepe.

Marx, K. y Engels, F. (1976b). Cuestiones de arte y literatura. Traducción del francés de Jesús López P. Barcelona: Península.

Melotti, H. (1975). Marx y el tercer mundo. Buenos Aires: Amorrortu.

Pelletier, A. y Goblot, J. (1975). Materialismo histórico e historia de las civilizaciones. México: Grijalbo.

Piaget, J. (1972). Lenguaje y pensamiento en el niño. Buenos Aires: Guadalupe. Piaget, J. (1975). Introducción a la epistemología genética: 2 El pensamiento físico. Buenos Aires: Paidós. 